\title{
Effect of anthropogenic emissions in East Asia on regional ozone levels during spring cold continental outbreaks near Taiwan: A case study
}

\author{
Chung-Ming Liu ${ }^{\text {a, }}$, Ming-Te Yeh ${ }^{a}$, Sahana Paul ${ }^{a}$, Y.-C. Lee ${ }^{\text {a }}$, D.J. Jacob ${ }^{\text {b }}$, M. Fu ${ }^{\text {, }}$, \\ J.-H. Woo ${ }^{\text {c }}$, G.R. Carmichael ${ }^{\text {c }}$, D.G. Streets ${ }^{\mathrm{d}}$ \\ ${ }^{a}$ Department of Atmospheric Sciences, National Taiwan University, Taiwan \\ ${ }^{\mathrm{b}}$ Department of Earth and Planetary Sciences, Division of Engineering and Applied Sciences, Harvard University, Boston, MA, USA \\ ${ }^{\mathrm{c}}$ Department of Chemical \& Biochemical Engineering, University of Iowa, Iowa City, IA, USA \\ ${ }^{\mathrm{d}}$ Decision and Information Sciences Division, Argonne National Laboratory, Argonne, IL, USA
}

Received 13 February 2006; received in revised form 22 August 2007; accepted 26 August 2007

Available online 7 November 2007

\begin{abstract}
A numerical simulation study to quantify the effect of upstream transport and fossil-fuel and biomass-burning emissions from East Asia on the surface ozone near Taiwan has been performed based on data taken April 8-13, 2001, when a cold air outbreak occurred. The TAQM (Taiwan Air Quality Model) is employed in this study. Results show that, without considering emissions in East Asia, upstream transport of chemical species associated with the movement of the cold air mass increased the levels of CO and ozone near Taiwan from 75 to 180 ppbv, and 35 to 55 ppbv, respectively. Fossil-fuel and biomass-burning emissions can thus result in a significant increase of CO and ozone levels (70-150\% and 50-100\%, respectively) from the emissionless background. The most noteworthy phenomenon is that biomass burning in Eastern China alone can contribute up to $20 \%$ of the increase for these species, while the biomass burning in Southeast Asia has negligible influence.
\end{abstract}

(C) 2007 Published by Elsevier Ltd.

Keywords: Surface ozone; Cold air outbreak; Anthropogenic emission; Numerical simulation

\section{Introduction}

Tropospheric ozone plays a significant role in controlling the chemical composition of the troposphere. Anthropogenic emissions reportedly exert a strong influence on the abundance of trace gases, like ozone, in the atmosphere (Crutzen and Andreae, 1990). The western Pacific is adjacent to the densely populated region of East Asia, which is a major source of anthropogenic emission. The outflow of chemically and radiatively important gases, aerosols, and their precursors from East Asia to the western Pacific are significant in spring (Wild and Akimoto, 2001). Taiwan is an island beside mainland East Asia and surrounded by the western Pacific.

\footnotetext{
* Corresponding author: Tel.: +886 2 83693622; fax: +886 223660412 .

E-mail address: liucm@ntu.edu.tw (C.-M. Liu).
}

Therefore, it has been noted by several groups that high ozone levels near Taiwan during winter, spring, and autumn can be traced to the frequent arrival of mid-troposheric air from northwestern China (Liu et al., 1995; Akimoto et al., 1996; Buhr et al., 1996). A number of field studies were therefore conducted, including both the Pacific Exploratory MissionWest Phase B (PEM-west B) study in February-March, 1994 (Hoell et al., 1997) and the Transport and Chemical Evolution over the Pacific (TRACE-P) aircraft mission in FebruaryApril 2001 (Jacob et al., 2003).

This study will analyze the effect of upstream ozone transport and photochemical production on the surface ozone level near Taiwan during spring. Photochemical production associated with precursors released from fossil fuel- (including biofuel) and biomass-burning sources in East Asia will be included. 
The study done by Woo et al. (2003) suggests dividing the biomass sources into three major categories for the Asian region: forest burning, savanna/grassland burning, and crop residue burning (in the field after harvest). Emitted non-methane hydrocarbon species with the potential to form atmospheric ozone come from several sources. Ethane, ethene, internal alkenes, and acetylene come from biofuel burning. Ethane, ethene, formaldehyde, and ketones are produced in biomass burning. In addition, propane, butane, ethane, and formaldehyde form from fossil-fuel burning (Klimont et al., 2002; Woo et al., 2003).

Biofuel emissions arise from the combustion of wood, animal waste (dung), and agricultural waste, and are commonly treated as an anthropogenic source. In contrast, biomass burning is treated as a partly natural, partly anthropogenic source. Hereafter, total anthropogenic emission estimates from Streets et al. (2003), which include the biofuel contribution, are named as the fossil-fuel emission in this paper, in contrast to the biomass-burning emission estimated by Woo et al. (2003).

In spring, cold air outbreaks frequently initiate dust storms over northern China and Mongolia (Liu et al., 2004). The Asian Pacific Regional Aerosol Characterization Experiment (ACE-Asia) was carried out from late March to early May of 2001 to focus specifically on the study of Asian aerosols. In the present work, a period that coincides with the so-called ACE-Asia "perfect storm" event that happened during April 4-13, 2001 (Tang et al., 2004) has been selected to perform the numerical simulation study.

A number of numerical simulation studies concerning the transport of dust particles (Gong et al., 2003; Liu et al., 2003; Uno et al., 2003; Satake et al., 2004; Arvarnitis and Moussiopoulous, 2006; Ginoux et al., 2004; Vautard et al., 2000), their mixing with anthropogenic pollutants, and their radiative effect (Chang and Park, 2004; Uno et al., 2004) have been considered on this perfect storm event. Tang et al. (2004) reported on the 3-D distribution of aerosols and chemical interactions in the atmosphere, and they concluded that heterogeneous reactions on dust involving $\mathrm{O}_{3}, \mathrm{NO}_{2}, \mathrm{SO}_{2}$, and $\mathrm{HNO}_{3}$ are capable of reducing the levels of these species and changing the chemical size distribution of the aerosols within the dust plume. Zhang et al. (2004) and Han (2007) also performed similar simulations to study ozone transport over East Asia during March 2001. In their studies, the effects of aerosols on atmospheric chemistry were ignored. None of these numerical studies attempted to quantify the individual effects of upstream transport, and anthropogenic fossil fueland biomass-burning emissions in East Asia.

In this paper, the Taiwan Air Quality Model (TAQM) (Chang et al., 2000), driven by the PSU/NCAR mesoscale model (known as MM5) (Grell et al., 1993), is applied to quantify the influence of the upstream transport of ozone and ozone production, due to precursors released from fossil fuel- and biomass-burning near Taiwan during April 8-13, 2001. The dust storm is the strongest event to trigger the outflow of precursors from land to ocean. Therefore, during dust storm activity, the effect of precursors on surface air quality downstream is expected to be high.

\section{Model set-up}

The TAQM was established by the Taiwan EPA in 1993 through modification of the Regional Acid Deposition Model (RADM) developed by the US National Acid Precipitation Assessment Program. The version used for this study is the second generation TAQM, established in 1999. The gas phase chemical mechanisms of the TAQM employ the RADM2 approach (transformation of 63 species in 158 reactions) that was developed by Stockwell et al. (1990). The inorganic chemical reactions involve 14 stable, four intermediate, and three abundant stable species. The organic chemical reactions are represented by 26 stable species and 16 peroxy radicals. The stable organic species include five alkanes (methane, ethane, and three higher lumped groups), four alkenes (ethene, terminal and internal alkenes, and isoprene), three aromatics (toluene, xylene, and cresol), six carbonyls (aldehydes, ketones and dicarbonyls), three organic peroxides, two organic acids (formic and acetic acid), two organic nitrates, and peroxyacyl nitrate (PAN). The photolysis rates are calculated as a function of daytime, latitude, and height for clear-sky conditions, and are then adjusted for the presence of clouds (Madronich, 1987).

The gas-phase photochemical reactions form the wellknown stiff system of differential equations. The TAQM utilizes the RADM chemistry solver (Chang et al., 1987), which is about five times faster than the Gear solver (Gear, 1971), which uses operator-splitting. The solver divides all the chemical species into four classes: families of closely interacting species, short-lived species (mostly radicals and intermediates), long-lived species, and a special radical grouping of $\mathrm{HO}$ and $\mathrm{HO}_{2}$. Different solution techniques are used for each of these classes. The model incorporates advanced numerical schemes to improve the precision and efficiency of computation. The transport scheme in the TAQM accounts for the horizontal and vertical advection, eddy diffusion, and local convective mixing that can occur with unstable weather conditions (Pleim and Chang, 1992). To avoid strong numerical diffusion, the Bott scheme (Bott, 1989) is adopted for the advection calculation.

It is possible for many uncertainties to affect the reliability of this calculation. For instance, aerosols may prompt heterogeneous reactions with the gas species. We have done a sensitivity study by reducing the production rate of ozone, $\mathrm{NO}_{2}$, $\mathrm{SO}_{2}$, and $\mathrm{HNO}_{3}$ by $6 \%$ (Tang et al., 2004) subjectively in every time step in order to represent the dust effect on heterogeneous uptake. The results show only about $\pm 5 \%$ change from the model output which does not consider the dust effect. Therefore, the effects of aerosols on the ozone chemistry were ignored in this study.

The TAQM is run from April 6-12 for two stages. In stage 1, April 6-8, referred to as pre-run, the TAQM is fed by MM5 (Mesoscale Model Version 5) output for meteorological parameter input at every integral step. The MM5 starts on 08LT, April 6, for the initiation of a three-dimensional distribution of chemical species, with the initial and boundary conditions obtained from Heald et al. (2003) from the 
GEOS-CHEM v.4.33 global 3-D model of tropospheric chemistry (http://www-as.harvard.edu/ chemistry/trop/geos) having $2 \times 2.5^{\circ}$ horizontal resolution and 48 vertical levels. The monthly-mean output of GEOS-CHEM in April 2001 was used to initiate the run and set the boundary condition at every integral step in this 3-day calculation. The GEOS-CHEM output allows the upstream effects from Northern America and Eurasia on regional air quality to be included. The MM5 meteorological simulations are run in non-hydrostatic mode, using data produced by the ECMWF's (European Centre for Medium-Range Weather Forecasts) assimilation system.

In stage 2, April 8-12, referred to as the final run, the MM5 output is again fed to the TAQM. The pre-run output from the TAQM was used for the initial and boundary conditions in this stage. The simulation outputs obtained from April 10-13 were used for this study. In this paper, LT stands for the local time, which is equivalent to -8UTC (Coordinated Universal Time).

Both MM5 and TAQM apply Cartesian coordinates in the horizontal domain, with Lambert conformal projection and $\sigma$-coordinates in the vertical direction. The model domain is set to the East Asian region covering an area from northern China and Mongolia to Taiwan and Southeast Asia. The horizontal grid resolution is fixed at $60 \mathrm{~km} \times 60 \mathrm{~km}$, with $99 \times 99$ grids. The vertical resolution is non-uniform. Both MM5 and TAQM are set to 24 layers in $\sigma$-coordinates, from the finest resolution of $\sim 40 \mathrm{~m}$ at the base to the coarser one of $\sim 2 \mathrm{~km}$ at the top. A 5-min time-step is used for both MM5 and the TAQM.

In general, to resolve the effect of the regional formation of ozone on the air quality of an urban polluted area, a detailed nesting approach in modeling is needed, as done by Moussiopoulos et al. (2006) for Thessaloniki, Greece. Meanwhile, to study the long range transport effect, a grid system with half-degree resolution is commonly applied, as done by Zunckel et al. (2006) for the southern Africa region. Although results from the nesting approach tend to give better temporal and quantitative variation of ozone close to the observation, the half-degree gridding approach tends to generate reasonable regional features, with limited computer resources needed. In this research, a $60 \mathrm{~km} \times 60 \mathrm{~km}$ grid system is applied for a region centered at Taiwan.

Emission data, which are a bottom up inventory driven by regional-specific information on fuels and activity from various economic sectors (e.g. domestic, transport, power generation, industrial), used in this calculation are based on Streets et al. (2003) and Woo et al. (2003). This emission inventory includes all anthropogenic sources, biomass-burning, volcanoes, and biogenic sources. Very detailed high-resolution emission data near the Taiwan region from the Taiwan EPA was included. A built-in program in the model has changed those high resolution datasets into the $60 \mathrm{~km} \times 60 \mathrm{~km}$ datasets that are required by the TAQM. In general, Asian emissions show strong regional differences which are discussed in detail by Woo et al. (2003). Fossil-fuel emissions dominate at high latitudes. Biomass burning dominates at lower latitudes, and biofuel is predominant in air masses coming from central China. Following the suggestion by Woo et al. (2003), the biofuel emission is included into the fossil-fuel emission data.
Carmichael et al. (2003) have used measurements obtained during the NASA Transport and Chemical Evolution over the Pacific (TRACE-P) experiment, from February to April 2001, in conjunction with regional modeling analysis to evaluate emission estimates for Asia. They have concluded that the inventory performs well for the light alkanes, $\mathrm{CO}$, ethyne, $\mathrm{SO}_{2}$, and $\mathrm{NO}_{x}$, and have noted that the emission inventories are of sufficient quality to support preliminary studies of ozone production.

\section{Results}

\subsection{Synoptic evolutions}

On April 8, at $500 \mathrm{hPa}$, a deep trough extending southwards from the eastern coast of Russia to southeastern China led the cold air southeastward to Taiwan. During the analysis period, two frontal systems passed through Taiwan, on April 9th (Fig. 1a) and 11th (Fig. 1b), respectively. The high pressure system over the northwestern corner of the simulation domain (Fig. 1a) was moving southeastward. The evolution of the synoptic system was simulated reasonably well by MM5. The air stream lines, shown in Fig. 1b for April 11th, clearly indicate the advance of cold air from the northwest corner of the simulation domain toward the Pacific. Along the eastern coast of China, a high level ozone patch was spreading along the frontal system toward the south (Fig. 1b). Over the Taiwan area, a northeasterly prevailed.

The backward trajectories for air parcels reaching the southeastern corner of Taiwan at 08LT on April 13 were derived separately by the NOAA HYSPLIT (Hybrid SingleParticle Lagrangian Integrated Trajectory) Model and MM5, and were compared with each other (figures not shown). This method can be taken as an indirect approach to validate the reliability of the MM5 simulation. The HYSPLIT model adopts the NOAA NCEP reanalysis dataset for this calculation. The air parcels are back-traced for $72 \mathrm{~h}$ on April 13, 2001 from the same starting point, Lanyu $\left(22^{\circ} 02^{\prime} \mathrm{N}\right.$ and $121^{\circ} 33^{\prime} \mathrm{E}$ ), at $10 \mathrm{~m}$ and $3000 \mathrm{~m}$ height, and with the same isobaric vertical motion options. The trajectories obtained from the MM5 simulation outputs are generally similar to those estimated by the HYSPLIT model.

\subsection{Comparison of model results with observation}

Data collected at five different stations along the eastern coast of Taiwan (Wanli, Yilan, Taitung, Lanyu, and Hengchun) (Figs. 2, 3) is compared with the model simulation outputs under the influence of both fossil fuel- and biomass-burning emissions in East Asia. These stations were selected because they were not affected by major pollution sources along the populated western coast under prevailing northeasterlies, though local influence may still affect the local air quality.

The CO levels at the northern tip of Taiwan (i.e. at Wanli) simulated by the model are higher than those observed levels on April 10, but get closer in the last 2 days (Fig. 2). Meanwhile, in the cities of Yilan and Taitung, local emissions 
(a)

2001/4/9 08LT

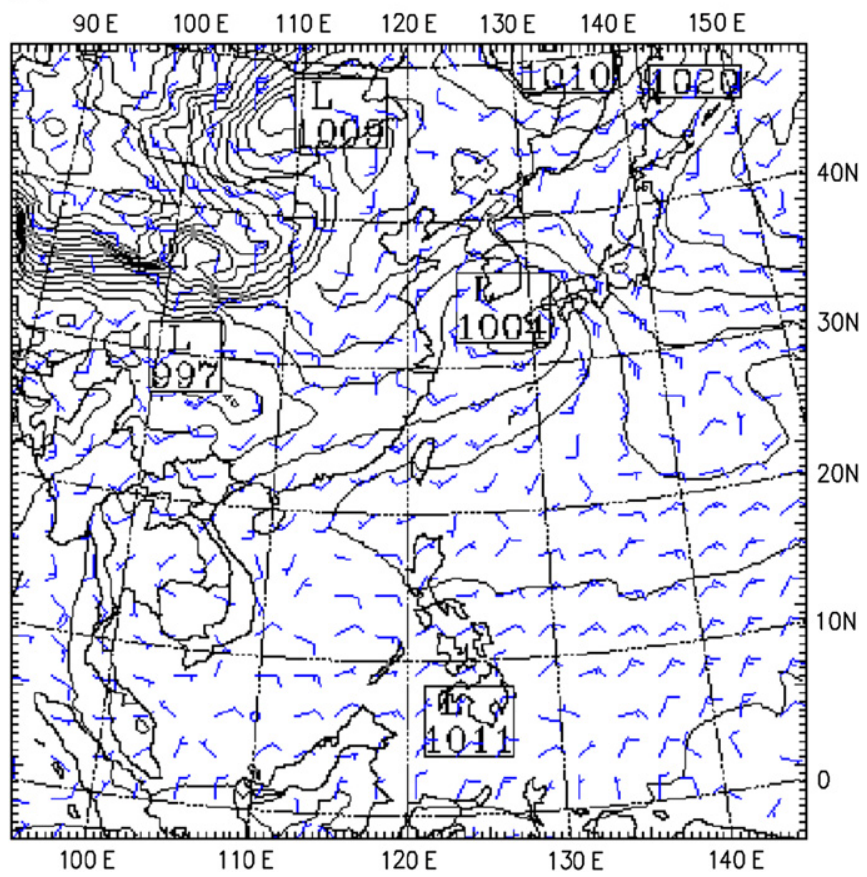

(b)

$2001 / 4 / 11$ 14LT

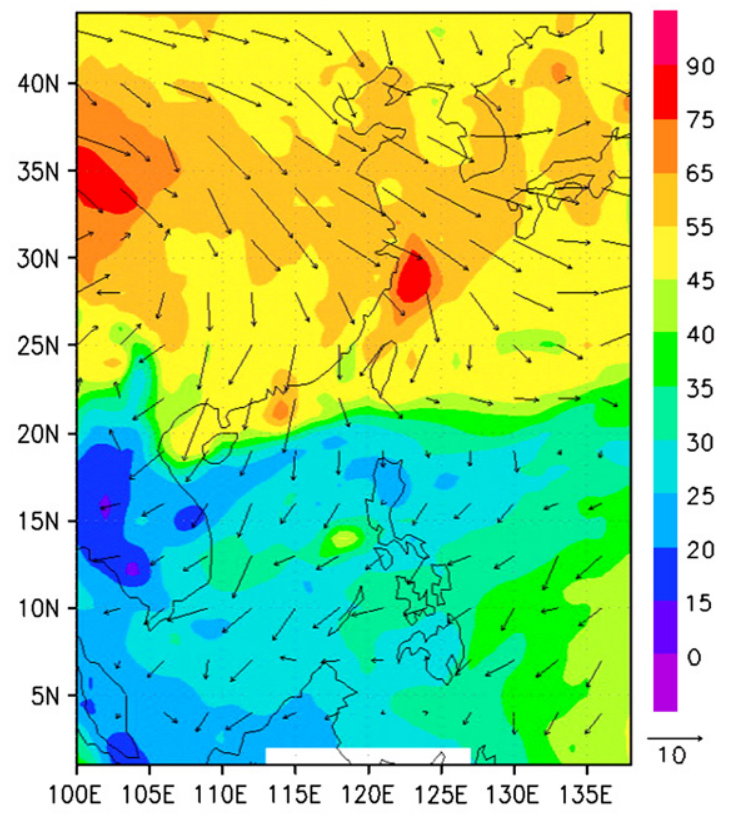

Fig. 1. (a) Contours of surface pressure and the distribution of wind vectors simulated by MM5 at 08LT on April 9 2001, and (b) streamlines at the surface with concentration of ozone at 14LT on April 11 2001. LT stands for the local time, which is equivalent to -8UTC.

clearly influence the measured $\mathrm{CO}$ levels, resulting in much higher $\mathrm{CO}$ levels than the model outputs, especially during daytime traffic hours. Such differences can be minimized if a nested approach is applied to downscale the TAQM model to the area near these stations. Still, the diurnal variation pattern is well captured at these three stations.

On the southeastern side of Taiwan (i.e. Lanyu) and at the southern tip of Taiwan (i.e. Hengchen), the simulated CO levels are slightly lower than the observed ones. The differences get smaller in the last simulation day. Meanwhile, the data collected at Hengchen shows an instrument detection limit of $300 \mathrm{ppbv}$, which could hamper the detection of detailed temporal and quantitative variation of $\mathrm{CO}$. In general, the passage of the cold front on April 11th brought in a polluted continental air mass and elevated the $\mathrm{CO}$ levels along the eastern coast of Taiwan.

For the comparison of ozone (Fig. 3), the model results for Wanli are quite close to the observation. But the model slightly
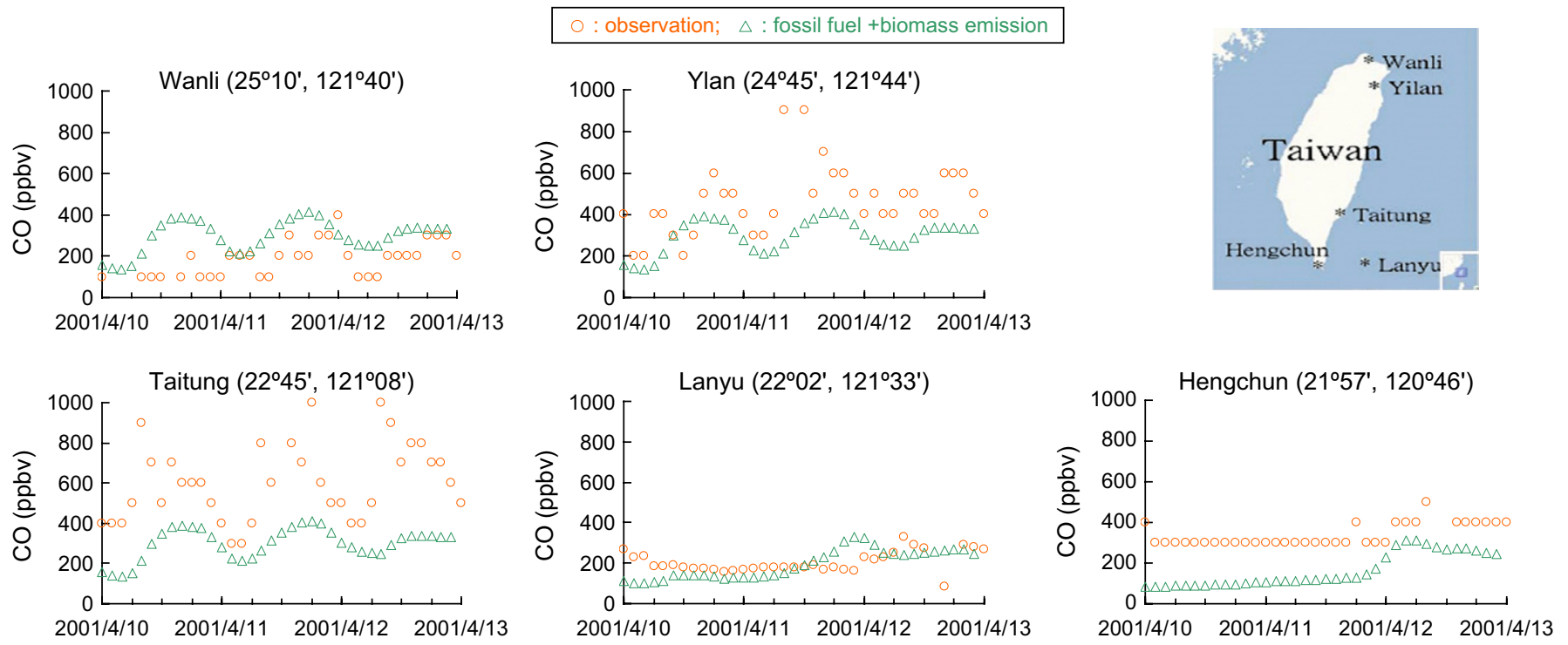

Fig. 2. The comparison of observation data with the model derived surface $\mathrm{CO}$ under fossil-fuel and biomass-burning emission conditions at five monitoring stations along eastern Taiwan. 
: observation; $\triangle$ : fossil fuel +biomass emission
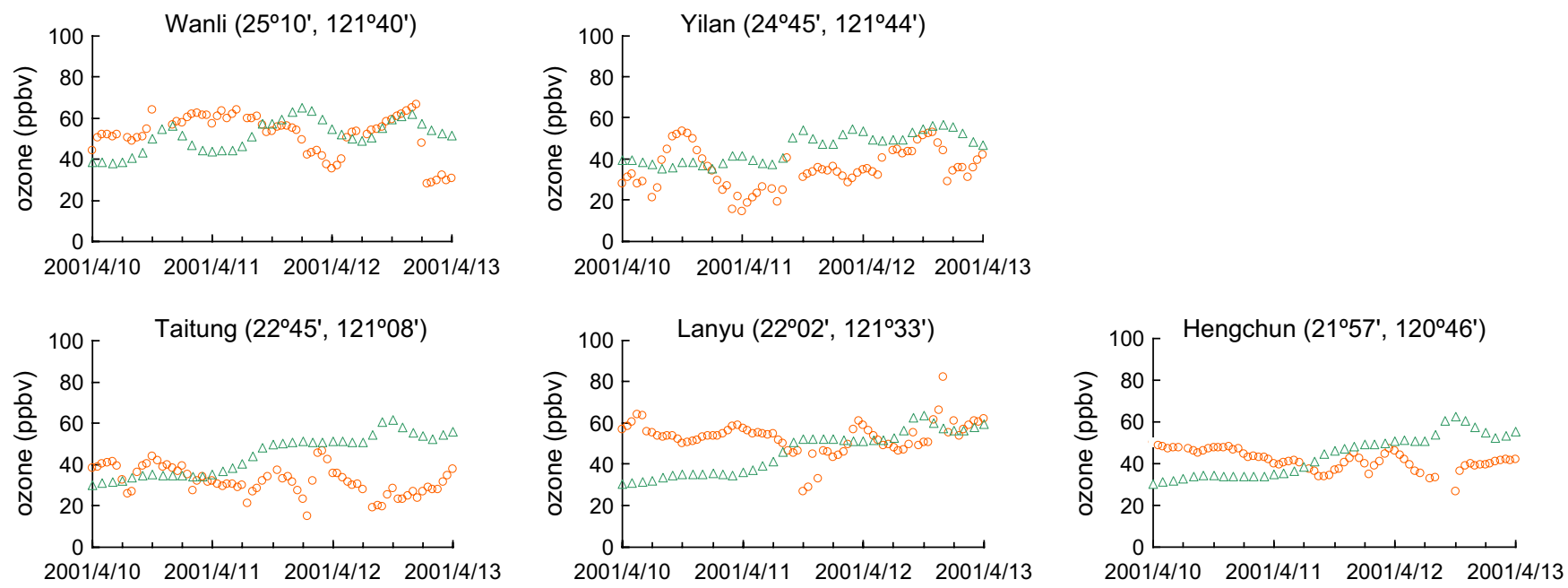

Fig. 3. The comparison of observation data with the model-derived surface ozone under fossil-fuel and biomass-burning emission conditions at five monitoring stations along eastern Taiwan.

overestimates the ozone level at Yilan and Taitung, most likely due to the local titration effect of vehicle-emitted NO, which reduces the ambient ozone level near the measurement sites. At Lanyu and Hengchun, the model underestimates the ozone levels before April 11, but then approaches the observed values. Such results also suggest the arrival of mainland polluted air after the passage of the cold front on April 11.

\subsection{Spatial and temporal evolution of surface carbon monoxide}

Carbon monoxide has a lifetime of about 2 months in the troposphere, with sources directly linked to upstream transport and anthropogenic emissions. Meanwhile, oxidation of $\mathrm{CO}$ through reaction with $\mathrm{OH}$ radicals is the major sink of CO. Its activity depends highly on the level of $\mathrm{OH}$. During the simulation period, a continent-ocean contrast exists in the contour plots of surface CO over East Asia (Fig. 4a), with high concentration near emission sources in China, Japan, Korea, Taiwan, and the Indochina Peninsula. Area-mean CO levels near Beijing and Shanghai reach 360 ppbv, with negligible diurnal variations. In contrast, over the western Pacific, south of $25^{\circ} \mathrm{N}$ latitude, area-mean $\mathrm{CO}$ concentration is about $120 \mathrm{ppbv}$ and less than $90 \mathrm{ppbv}$ over the sea surface at the southwestern corner of the simulation domain.

On April 8, a wide tongue of surface CO, with area-mean level ranging from 210 to $390 \mathrm{ppbv}$, extended from the southeastern corner of Russia toward the Yangtze River. This high $\mathrm{CO}$ concentration patch gradually expanded southward and eastward along with the movement of the cold air-mass. On April 11, it merged with emissions from biomass-burning sources in the Indochina Peninsula area. A frontal line of CO with a level higher than $210 \mathrm{ppbv}$ appeared over Japan, Taiwan, and from Hainan Island to Vietnam on April 11. Then the frontal line gradually moved toward the east. On April 13, a wide patch of CO appeared, covering almost all of eastern China, including the Indochina Peninsula and the northern part of the Western Pacific. Over the coastline of China, the CO concentration was as high as $390 \mathrm{ppbv}$. Eventually, around Taiwan, the concentration of $\mathrm{CO}$ rose up to 360 ppbv. Before April 10, the area-mean CO level over the sea surface around Taiwan was $90-120$ ppbv. However, this concentration grows to more than $330 \mathrm{ppbv}$ after the eastward expansion of the high concentration $\mathrm{CO}$ patch, whose advancement over the frontal passage eventually covered Taiwan.

Results from the model simulated without all East Asian emissions are shown in Fig. 4b. In this case, the movement of the cold air-mass can still be identified by taking the advancement of the $210 \mathrm{ppbv} \mathrm{CO}$ patch as a marker. This 210 ppbv CO patch is small on April 8, and exists only in the northwestern corner of the domain. The patch then expands southward and has occupied nearly half of the simulation region by the end of the simulation period on April 13 . The effect of the Tibetan Plateau that blocks the air flow near sea-level can be distinguished by the protruding tongue of the $180 \mathrm{ppbv} \mathrm{CO}$ contour line along the border of the Plateau southward to Hainan. The area-mean level of surface $\mathrm{CO}$ near Taiwan increased from 75 to 180 ppbv from April 8 to 13 . However, there is no high-level CO puff. This event is directly linked to the fixed upstream transported $\mathrm{CO}$ level along the western border of the simulation domain. According to Akimoto et al. (1996), steady inflows from Europe and America have significant effects on the atmospheric chemistry field in the East Asian Pacific rim region.

To quantify the effect of anthropogenic fossil-fuel and biomass-burning emission on the evolution of atmospheric chemical species, the percentage change, $p$ (Fig. 5a), can be estimated by subtracting the without-emission result, $C_{\text {wo }}$, from the with-emission result, $C_{\mathrm{w}}$, and then dividing the remainder by the former value, i.e. 

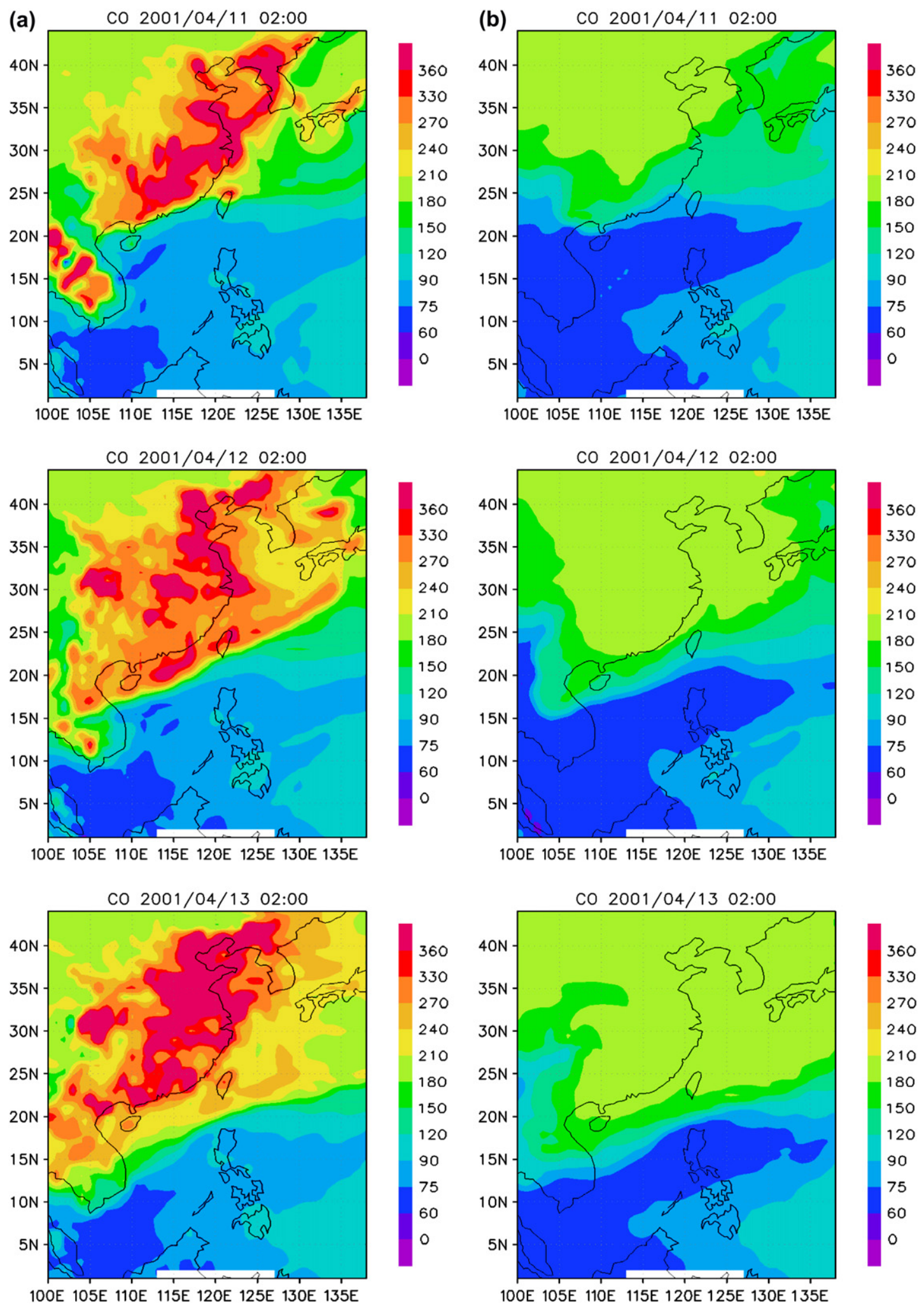

Fig. 4. Distributions of surface CO (ppbv) at 02 LT on April 11-13, 2001 simulated by TAQM (a) with emissions from fossil-fuel and biomass-burning sources and (b) without emissions in the simulation domain. 

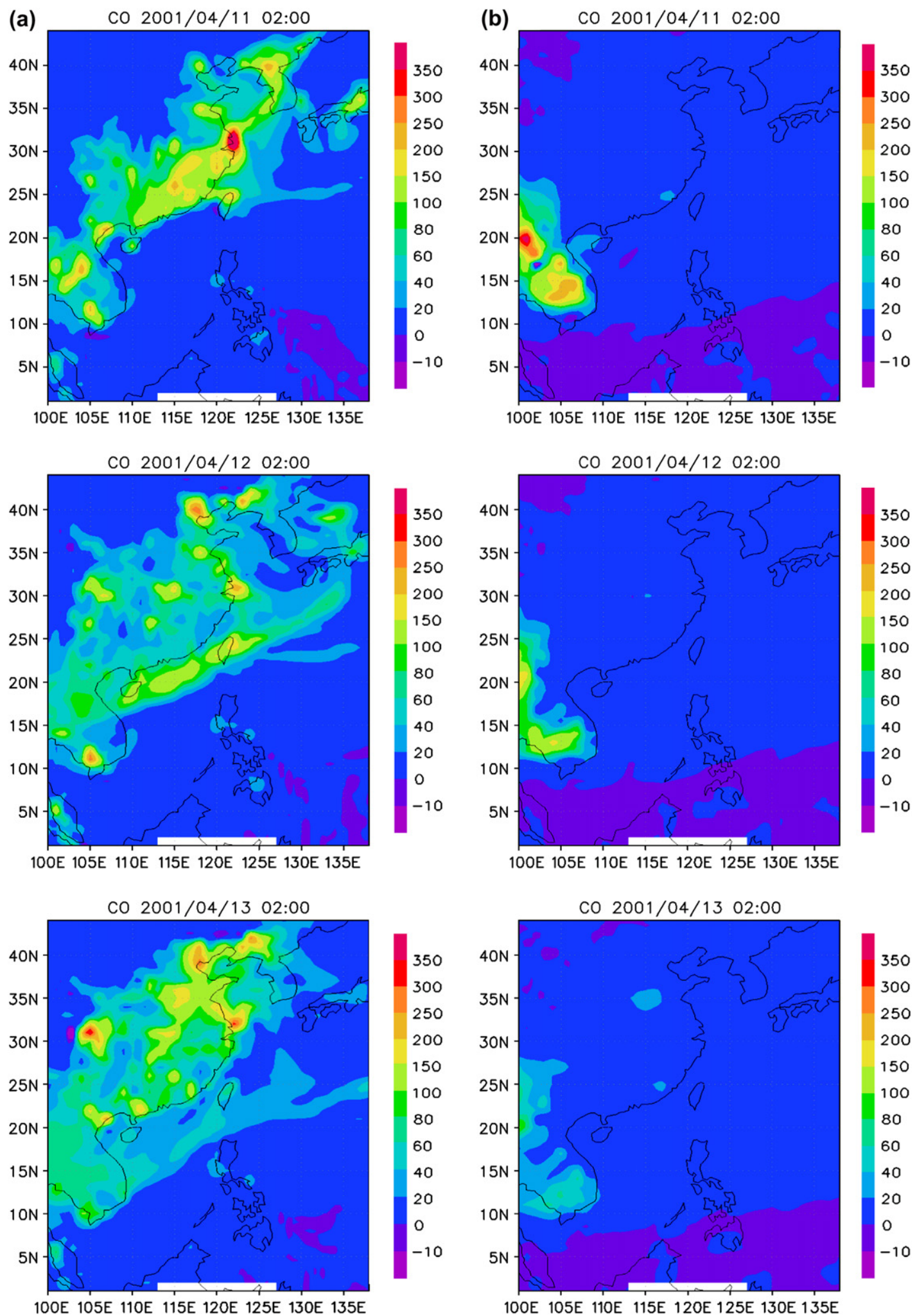

Fig. 5. Distributions of the percentage change (\%) of surface CO at 02 LT during April 11-13, 2001 with emissions from (a) fossil-fuel and biomass-burning sources and (b) biomass-burning sources only with respect to those obtained without emissions in the simulation domain. 
$p=\frac{C_{\mathrm{w}}-C_{\mathrm{wo}}}{C_{\mathrm{wo}}} \times 100 \%$

The without-emission result can be taken as the contribution due to upstream transport from outside the simulation domain. The with-emission result captures the pollution level due to both upstream transport and emission. The same approach is applied on the analysis of the biomass-burning-only contribution (Fig. 5b). Meanwhile, the calculation of the percentage change can generate negative values at the border of the simulation domain, implying that the without-emission result is higher than that with emission. Under the emission case, chemically destructive reactions of interested species with pollutants outside of the emission sources are abundant. For CO, active oxidation downstream, away from the emission sources could cause the occurrence of negative percentage change at the southern border of the simulation domain. Such a phenomenon is particularly clear in the biomass-burning-only case (Fig. 5b). However, for ozone (Figs. 6, 7), more destructive reactions occur in areas near emission sources, and the gradienttransport effect will then pull molecules out of unpolluted areas toward the polluted regions. In this case, the upstream clean region will be affected much more significantly than the downstream photochemical-production area. Hence, in Fig. 7 , the negative percentage change areas dominate over the northwestern corner of the simulation domain, although some negative percentage change areas are also distinguishable over the southeastern corner.

On April 8, before the initiation of the southeastward movement of the cold air-mass, the contribution from anthropogenic sources was responsible for the $80-350 \%$ increase in CO levels near emission sources in China (Fig. 5a). A wide, elongated patch with increased $\mathrm{CO}$ levels of up to $250 \%$ spread over the land along the coastline on April 8. Some discrete points, including the Indochina Peninsula, experienced CO levels increases of up to $350 \%$. This particular CO patch has a diurnal variation with higher $\mathrm{CO}$ concentration at night. The CO level increases at night by about $60 \%$ near Taiwan and $20 \%$ over the Western Pacific with respect to the without-emission case. After April 10, the patch started to spread from the land towards the ocean, decreasing the $\mathrm{CO}$ level over land (Fig. 5a). By April 12, the CO concentration had increased to $150 \%$ with some discrete patches of $200 \%$ over the Western Pacific. By April 13, the arrival of upstream pollutants had enhanced the level by $60 \%$ around the Taiwan region. Such enhancement is actually more pronounced during nighttime than in daytime.

Due to the contribution of biomass burning (Fig. 5b), a $100-350 \%$ increase of the CO level over the Indo-China Peninsula can be observed with a significant diurnal variation. The CO level is comparatively high in nighttime with respect to daytime.

After studying the expansion of the vertical concentration of $\mathrm{CO}$, it has been noted that the remnant from fuel-burning sources can enhance the CO level by $60 \%$ at around $5 \mathrm{~km}$ in height and $100 \%$ at $2 \mathrm{~km}$ in height over the area between $10^{\circ} \mathrm{N}$ and $30^{\circ} \mathrm{N}$ along $105^{\circ} \mathrm{E}$ longitude. It should be noted that the highest emissions are observed in this area.

\subsection{Spatial and temporal evolution of surface ozone}

Ozone is a photochemical product, and its concentration is affected not only by the abundance of available precursors, but also by the effectiveness of air-flow transport. Stagnant airflow with sufficient sunshine favors the accumulation of local ozone in polluted urban areas. However, the transportation of ozone molecules from the mid-troposphere over northern China during each cold air-mass outbreak in spring, autumn, and winter plays a crucial role in enhancing the area-mean ozone level around Taiwan. The upstream transported ozone level is lowered significantly in summer, due to the inflow of clean marine air from the Pacific.

Model simulated results in the presence of all emission sources are plotted in Fig. 6a. In general, the southward movement of the 45 ppbv contour line signifies the transport of the mainland air mass onto the Pacific Ocean surface. Higher ozone levels are found over China, Japan, and Korea north of $25^{\circ} \mathrm{N}$, with significant diurnal variation in areas near emission sources. In the meantime, over the downstream of Shanghei (i.e. over the ocean surface between Shanghei and Taiwan), a high-level ozone plume can be identified with a noontime peak up to $90 \mathrm{ppbv}$. This plume gradually moves southward and causes the ozone level around the Taiwan region to increase from $40 \mathrm{ppbv}$ to $70 \mathrm{ppbv}$. As for the northwestern corner of the simulation domain, high area-mean ozone levels, around $55 \mathrm{ppbv}$, are stagnant due to a steady upstream transport influence (Fig. 6b).

Over most of the Western Pacific, the surface ozone level is around $55 \mathrm{ppbv}$ before the arrival of the first cold front, i.e. before April 9. During the cold front passage, the level drops to $30 \mathrm{ppbv}$ over the maritime area around Taiwan, due to the scavenging effect of rainfall. On April 10, high ozone concentrations up to $75 \mathrm{ppbv}$ are observed over land. Then, after April 10, the higher ozone region starts spreading eastward due to the passing of the polluted cold air mass towards the east. Therefore, increases in the ozone level of up to 75 ppbv over the Western Pacific are noted. The level of ozone increases to $75 \mathrm{ppbv}$ over the Taiwan Straits (the marine area between Taiwan and China) after April 10. A diurnal variation in ozone level is recognizable over this area, with the patch extending over a greater area during the nighttime. At the time of the arrival of the second cold front, a deep patch of dense ozone, with levels up to $90 \mathrm{ppbv}$, is seen over the marine area between Taiwan and Shanghai on April 11 at 14 LT.

Model simulated results, in the absence of emission from the sources (Fig. 6b), show that the ozone level over land is up to 75 ppbv. However, this high concentration is confined to a small region of the northwest corner of the domain on April 8. Most of the land and ocean is covered by an ozone level of $40 \mathrm{ppbv}$ on that day. A small patch of 75 ppbv also occurs in the northeast. Over the Taiwan region, a very low ozone level of $35 \mathrm{ppbv}$ appears on April 8. After April 10, the higher level ozone patch in the northwest corner has 

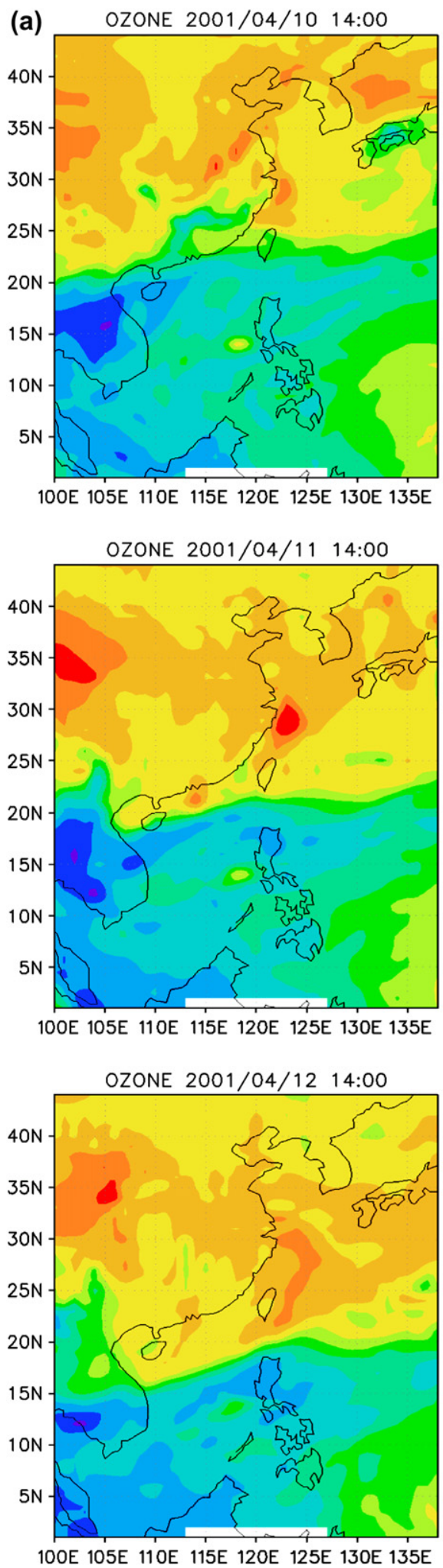
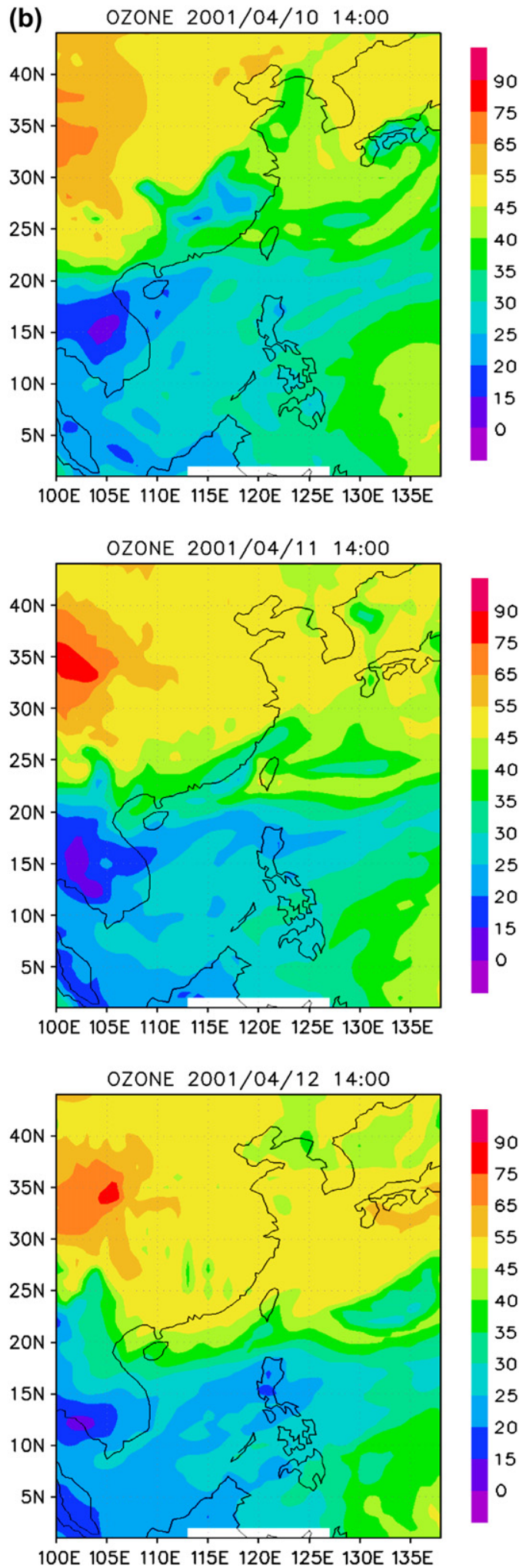

Fig. 6. Distributions of surface $\mathrm{O}_{3}$ (ppbv) at 14 LT during April 10-12, 2001 simulated by TAQM (a) with emissions from the fossil-fuel and biomass-burning sources and (b) without emissions in the simulation domain.

started to spread towards the Pacific. After April 12, most of the land and ocean are covered with a 55 ppbv ozone level. Eventually, there is a rise of the ozone level up to $55 \mathrm{ppbv}$ over the ocean, accompanied by a simultaneous decrease of ozone level over land, down to $35 \mathrm{ppbv}$ in the nighttime. These results show the transportation of ozone from the land along with the cold air mass.

To analyze the contribution of anthropogenic emissions to the increase in ozone level, the percentage change in surface ozone due to fossil-fuel and biomass burning emissions is 


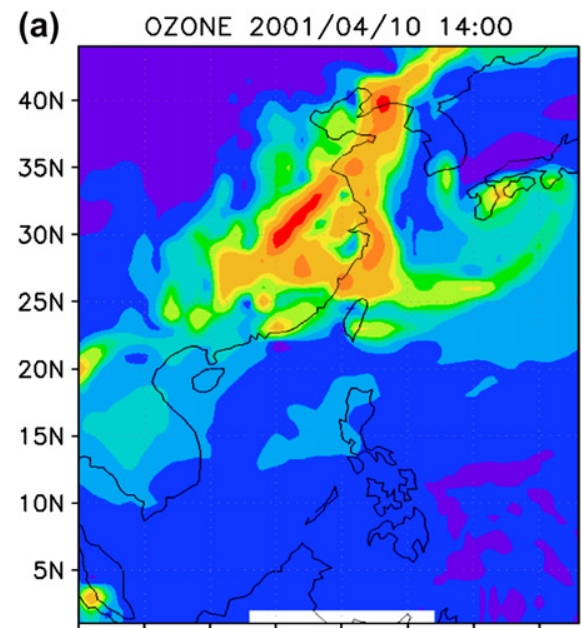

100E 105E 110E 115E 120E 125E 130E 135E

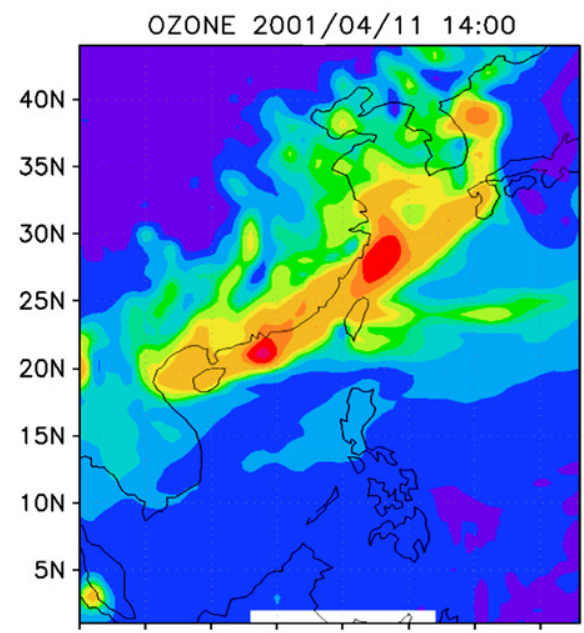

100E 105E 110E 115E 120E 125E 130E 135E

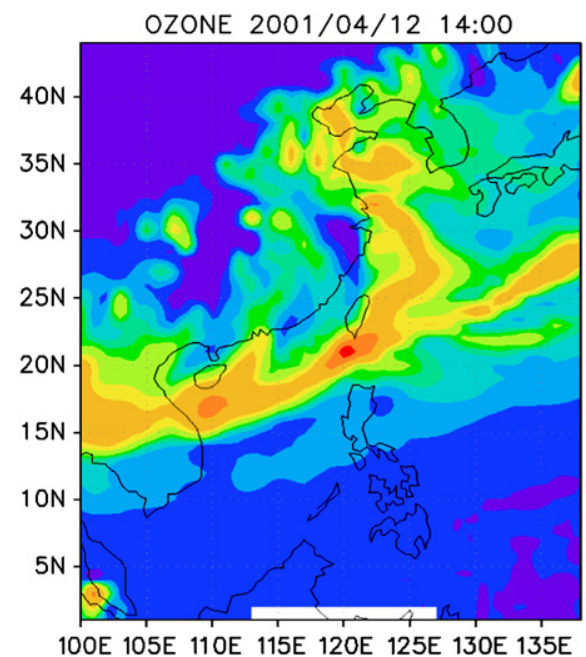

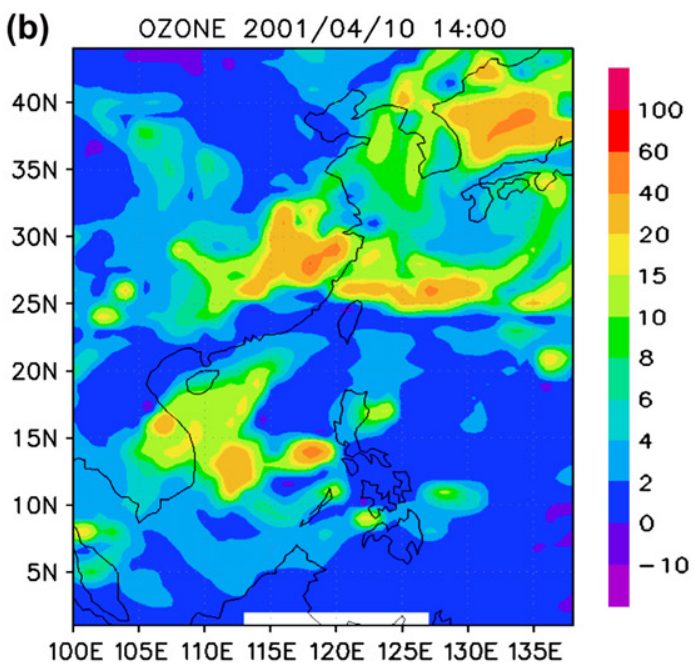
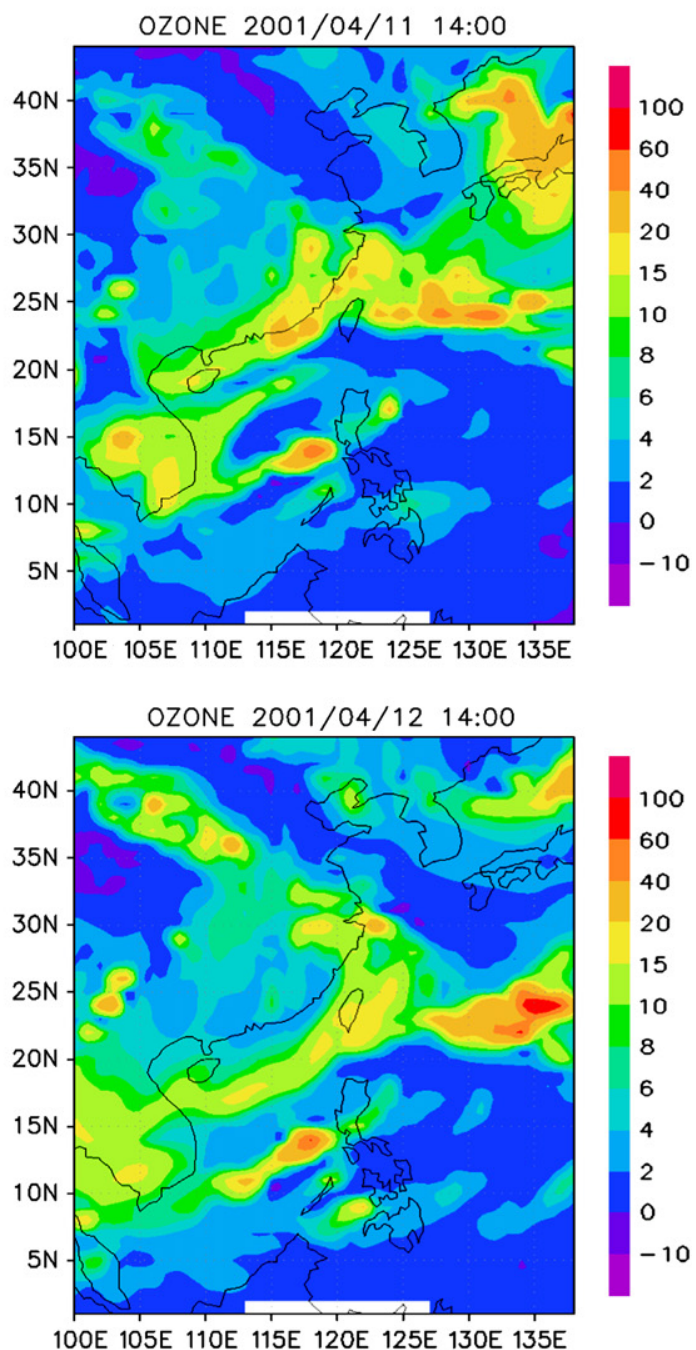

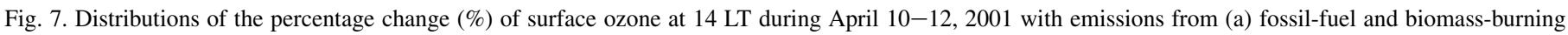
sources and (b) biomass-burning sources only with respect to those obtained without emissions in the simulation domain.

considered. The percentage change of ozone is calculated in the same way as $\mathrm{CO}$, and is presented in Fig. 7a. Up to a $100 \%$ increase in ozone level occurs at emission sources over the land, on April 9. On the other hand, around the
Taiwan region, the percentage increase is $20 \%$ on that day. After April 10, the high level ozone path is shifted from the land towards the ocean. On April 11 at 14 LT, an almost 100\% increase in ozone level is seen over the sea between Taiwan and 

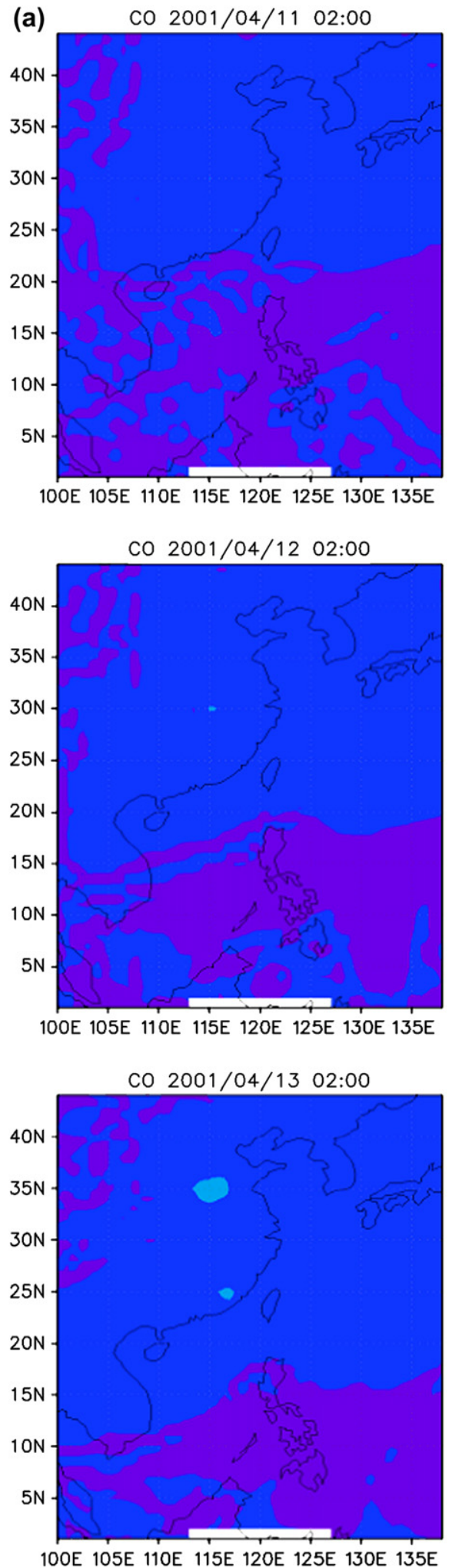
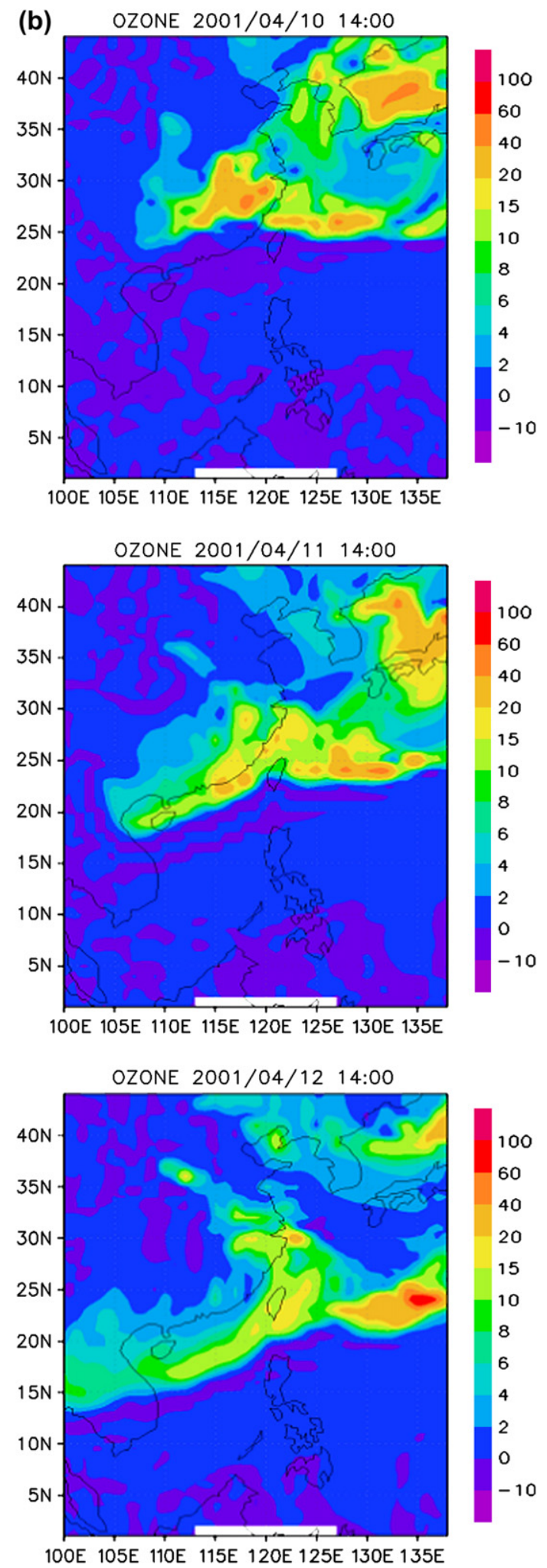

Fig. 8. Distributions of the percentage change (\%) of (a) CO at 02 LT and (b) surface ozone at 14 LT during April 10-13, 2001 with biomass-burning-only emissions (excluding sources in Southeast Asia and Western China) with respect to those obtained without emissions in the simulation domain.

Shanghai, and near the coast of Hong Kong. At night at 02 LT, a $100 \%$ increase of ozone level is recorded over Taiwan. On April 12, almost the whole patch shifted over the ocean, and therefore, the land became clean. This cleansing occurred because the northeasterly flow of the air-mass brought all the pollutants from the land to the ocean. This process can be clearly understood from the streamline flow presented in Fig. 1b. 
The percentage change in ozone level due to biomass-burning shows a deep patch, demonstrating a $60 \%$ increase (Fig. 7b) over land. However, the ocean is almost clean on April 9 at 2 LT. Over the Taiwan region, the increase is only 10\%. On April 11, the deep patch is shifted to the ocean. Therefore, the ozone level over Taiwan increases by $20 \%$. The ozone level increases up to $100 \%$ over the Western Pacific. These facts again confirm the transportation of pollutants from the mainland to the ocean along with the northeasterly flow.

The model is again run to simulate the $\mathrm{CO}$ and ozone level due to biomass burning from Eastern China, excluding emissions from South East Asia and Western China (Fig. 8). The results show a negligible difference near Taiwan compared to the above case which includes biomass-burning from the total East Asian domain (Figs. 5b and 7b). Therefore, the model confirms that, in the biomass-burning case, the ozone levels near Taiwan are mainly affected by biomass-burning emissions from Eastern China.

Finally, to see the effect of emissions from Taiwan, the pollution level due only to Taiwan anthropogenic emissions is simulated over the domain. The results indicate that the effects of Taiwan emissions on downstream regions are recognizable after April 11, after the passage of the second frontal system and prevailing of the northeasterlies. The region has only extended to the northern Philippines by April 13. For areas near Taiwan, Figs. $4-7$ present the general features.

\section{Conclusion}

Cold air outbreaks usually carry a huge amount of materials out of the mainland toward the western Pacific. However, outflows are most influential on downstream surface ozone during spring and in each dust storm event. In this study, the evolution of the photochemical field during a perfect dust storm event on April 6-13, 2001 has been simulated and analyzed. For the case with only upstream transport, the movement of the air mass resulted in the surface $\mathrm{CO}$ and ozone level near Taiwan increasing from 75 to $180 \mathrm{ppbv}$, and 35 to $55 \mathrm{ppbv}$, respectively. By including the fossil-fuel and biomass-burning emissions in East Asia, significant increases in $\mathrm{CO}$ and ozone levels, of $70-150 \%$ and $50-100 \%$, respectively, are noted. Biomass-burning in Eastern China contributes up to $20 \%$ of the increase for these species. Biomass-burning in Southeast Asia has a negligible influence near the surface, though it is important for the chemistry field at higher altitudes.

A sensitivity study that tested the effect of heterogeneous reactions associated with aerosols and other gases on reducing the productivity of each species suggested a negligible effect on the surface ozone field. Therefore, in this study, the aerosol effect on ozone chemistry has been ignored. In the future, we will simulate the evolution of dust transport and the chemistry field simultaneously, to quantify such effects for a much longer period, e.g. 1 month. As for the evaluation of the effect of Taiwan emissions on downstream regions, a much longer period of simulation is also needed to generate sufficient information.

\section{Acknowledgements}

This research was supported by grants from National Science Council of ROC, NSC 93-2119-M-002-014, NSC 942111-M-002-008 and NSC 95-2111-M-002-021. The authors thank the Taiwan EPA and the Central Weather Bureau for providing all necessary data for analysis. We also appreciate the convenience of using the on-line HYSPLIT model developed by US NOAA Air Resources Laboratory. The valuable comments from anonymous reviewers are sincerely appreciated. Finally, the authors appreciate the effort of Asia Science Editing, Ms F. Vicky and the American Journal Experts on polishing the paper.

\section{References}

Akimoto, H., Mukai, H., Nishikawa, M., Murano, K., Hatakeyama, S., Liu, C.-M., Buhr, M., Hsu, K.J., Jaffe, D.A., Zhang, L., Honrath, R., Merrill, J.T., Newell, R.E., 1996. Long-range transport of ozone in the East Asian Pacific rim region. J. Geophys. Res. 101, 1999-2010.

Arvarnitis, A., Moussiopoulous, N., 2006. Estimating long term urban exposure to particular matter and ozone in Europe. Environ. Model. Software 21, 447-453.

Bott, A., 1989. A positive definite advection scheme obtained by nonlinear renormalization of the advective fluxes. Mon. Weather Rev. 117, 1006-1015.

Buhr, M.P., Hsu, K.-J., Liu, C.M., Liu, R., Wei, L., Liu, Y.-C., Kuo, Y.-S., 1996. Trace gas measurements and air mass classification from a ground station in Taiwan during the PEM-West A experiment (1991). J. Geophys. Res. 101, 2025-2035.

Carmichael, G.R., Tang, Y., Kurata, G., Uno, I., Streets, D., Thongboonchoo, N., Woo, J.H., Gutikunda, S., White, A., Wang, T., Blake, D.R., Atlas, E., Fried, A., Potter, B., Avery, M.A., Sachse, G.W., Sandholm, S.T., Kondo, Y., Talbot, R.W., Bandy, A., Thorton, D., Clarke, A.D., 2003. Evaluating regional emission estimates using the Trace-P observations. J. Geophys. Res. 108 (D21), 8810, doi:10.1029/2002JD003116.

Chang, J.-S., Brost, R.A., Isaken, I.S.A., Madronich, S., Middleton, P., Stockwell, W.R., Walcek, C.J., 1987. A three-dimensional Eulerian acid deposition model physical concept and formulation. J. Geophys. Res. 92 , $14681-14700$.

Chang, K.-H., Jeng, F.-T., Tsai, Y.-L., Lin, P.-L., 2000. Modeling of long-range transport on Taiwan's acid deposition under different weather conditions. Atmos. Environ. 34, 3281-3295.

Chang, L.-S., Park, S.-U., 2004. Direct radiative forcing due to anthropogenic aerosols in East Asia during April 2001. Atmos. Environ. 38, 4467-4482.

Crutzen, P.J., Andreae, M.O., 1990. Biomass burning in the tropics. Impact on atmospheric chemistry and biogeochemical cycle. Science 250, 1669-1678.

Gear, C., 1971. Numerical Initial Value Problems in Ordinary Different Equation. Prentice-Hall, Englewood Cliffs, NJ.

Gong, S.L., Zhang, X.Y., Zhao, T.L., McKendry, I.G., Jaffe, D.A., Lu, N.M., 2003. Characterization of soil dust aerosol in China and its transport and distribution during 2001 ACE-Asia: 2. Model simulation and validation. J. Geophys. Res. 108 (D9), doi:10.1029/2002JD002633.

Grell, G.A., Dudhia, J., Stauffer, D.R., 1993: A description of the fifth-generation Penn State/NCAR mesoscale model (MM5). NCAR Technical Note, NCAR/TN-398\#STR. Boulder, CO, 117 pp.

Ginoux, P., Prospero, J.M., Torres, O., Chin, M., 2004. Long-term simulation of global dust distribution with the GOCART model: correlation with North Atlantic Oscillation. Environ. Model. Software 19, 113-128.

Han, Z., 2007. A regional air quality model: evaluation and simulation of $\mathrm{O}_{3}$ and relevant gaseous species in East Asia during spring 2001. Environ. Model. Software 22, 1328-1336.

Heald, C.L., Jacob, D.J., Fiore, A.M., Emmons, L.K., Gille, J.C., Deeter, M.N., Warner, J., Edwards, D.P., Crawford, J.H., Hamlin, A.J., Sachse, G.W., Browell, E.V., Avery, M.A., Vay, S.A., Westberg, D.J., Blake, D.R., Singh, H.B., Sandholm, S.T., Talbot, R.W., Fuelberg, H.E., 2003. Asian 
outflow and transpacific transport of carbon monoxide and ozone pollution: an integrated satellite, aircraft and model perspective. J. Geophys. Res. 108 (D24), 4804, doi:10.1029/2003JD003507.

Hoell, J.M., Davis, D.D., Liu, S.C., Newell, R.E., Akimoto, H., McNeal, R.J., Bendura, R.J., 1997. The Pacific Exploratory Mission-West Phase B: February-March, 1994. J. Geophys. Res. 102, 28223-28239.

Jacob, D.J., Crawford, J.H., Kleb, M.M., Connors, V.E., Bendura, R.J., Raper, J.L., Sachse, G.W., Gille, J.C., Emmons, L., Heald, C.L., 2003. The Transport and Chemical Evolution over the Pacific (TRACE-P) aircraft mission: design, execution, and first results. J. Geophys. Res. 108 (D4), 9000, doi:10.1029/2002JD003276.

Klimont, Z., Streets, D.G., Gupta, S., Cofala, J., Fu, L., Ichikawa, Y., 2002. Anthropogenic emissions of non-methane volatile organic compounds in China. Atmos. Environ. 36, 1309-1322.

Liu, C.M., Buhr, M.P., Lo, J.-G., Tso, T.-L., Hsu, K.J., Wang, J.-T., Merrill, J.T., Liu, S.C., 1995. A study of Taiwan background atmosphere. J. Terrestrial Atmos. Oceanic Sci. (TAO) 6, 419-442.

Liu, C.-M., Qian, Z.-A., Wu, M.-C., Song, M.-H., Liu, J.-T., 2004. A composite study of the synoptic differences between major and minor dust storm springs over the China-Mongolia areas. TAO 15, 999-1018.

Liu, M., Westphal, D.L., Wang, S., Shimizu, A., Sugimoto, N., Zhou, J., Chen, Y., 2003. A high-resolution numerical study of the Asian dust storms of April 2001. J. Geophys. Res. 108 (D23), 8653, doi:10.1029/ 2002JD003178.

Madronich, S., 1987. Photodissociation in the atmosphere: 1. actinic flux and the effects of ground reactions and clouds. J. Geophys. Res. 92, 9740-9752.

Moussiopoulos, N., Papalexiou, S., Sahm, P., 2006. Wind flow and photochemical air pollution in Thessaloniki, Greece. Part I: Simulations with the European Zooming Model. Environ. Model. Software 21, 1741-1751.

Pleim, J.E., Chang, J.S., 1992. A non-local closure model for vertical mixing in the convective boundary layer. Atmos. Environ. 26A, 965-981.

Satake, S., Uno, I., Takemura, T., Carmichael, G.R., Tang, Y., Streets, D., Sugimoto, N., Shimizu, A., Uematsu, M., Han, J.-S., Ohta, S., 2004. Characteristics of Asian aerosol transport simulated with a regional-scale chemical transport model during the ACE-Asia observation. J. Geophys. Res. 109 (D19), D19S22, doi:10.1029/2003JD003997.

Stockwell, W.R., Middleton, P., Chang, J.S., 1990. The second generation regional acid deposition model chemical mechanism for regional air quality modeling. J. Geophys. Res. 95 (D10), 16343-16367.

Streets, D.G., Bond, T.C., Carmichael, G.R., Fernandes, S.D., Fu, Q., He, D., Klimont, Z., Nelson, S.M., Tsai, N.Y., Wang, M.Q., Woo, J.-H.,
Yarber, K.F., 2003. An inventory of gaseous and primary aerosol emissions in Asia in the year 2000. J. Geophys. Res. 108 (D21), 8809, doi:10.1029/ 2002JD003093.

Tang, Y., Carmichael, G.R., Kurata, G., Uno, I., Weber, R.J., Song, C.-H., Guttikunda, S.K., Woo, J.-H., Streets, D.G., Wei, C., Clarke, A.D., Huebert, B., Anderson, T.L., Clarke, A.D., 2004. The impacts of dust on regional tropospheric chemistry during the ACE-ASIA Experiment: a model study with observations. J. Geophys. Res. 109, D19S21, doi:10.1029/2003JD003806.

Uno, I., Carmichael, G.R., Streets, D.G., Tang, Y., Yienger, J.J., Satake, S., Wang, Z., Woo, J.-H., Guttikunda, S., Uematsu, M., Matsumoto, K., Tanimoto, H., Yoshioka, K., Iida, T., 2003. Regional chemical weather forecasting system CFORS: model descriptions and analysis of surface observations at Japanese island stations during the ACE-Asia experiment. J. Geophys. Res. 108 (D23), 8668, doi:10.1029/2002JD002845.

Uno, I., Satake, S., Carmichael, G.R., Tang, Y., Wang, Z., Takemura, T., Sugimoto, N., Shimizu, A., Murayama, T., Cahill, T.A., Cliff, S., Uematsu, M., Ohta, S., Quinn, P.K., Bates, T.S., 2004. Numerical study of Asian dust transport during the springtime of 2001 simulated with the Chemical Weather Forecasting System (CFORS) model. J. Geophys. Res. 109, D19S24, doi:10.1029/2003JD004222.

Vautard, R., Beekmann, M., Menut, L., 2000. Applications of adjoint modeling in atmospheric chemistry; sensitivity and inverse modeling. Environ. Model. Software 15, 703-709.

Wild, O., Akimoto, H., 2001. Intercontinental transport and chemical transformation of ozone and its precursors from East Asia. In: Matsuno, T., Kida, H. (Eds.), Present and Future of Modeling Global Environmental Change: Toward Integrated Modeling. Terrapub, Tokyo, pp. 375-382.

Woo, J.-M., Streets, D., Carmichael, G.R., Tang, Y., Yoo, B.-I., Lee, W.-C., Thongboonchoo, N., Pinnock, S., Kurata, G., Uno, I., Fu, Q., Vay, S., Sachse, G.W., Blake, D.R., Fried, A., Thornton, D.C., 2003. The contribution of biomass and biofuel emissions to trace gas distributions in Asia during the TRACE-P experiment. J. Geophys. Res. 108 (D21), 8812, doi:10.1029/2003JD003200.

Zhang, M., Xu, Y., Uno, I., Akimoto, H., 2004. A numerical study of tropospheric ozone in the springtime in East Asia. Adv. Atmos. Sci. 21 (2), $163-170$.

Zunckel, M., Koosailee, A., Yarwood, G., Maure, G., Venjonoka, K., van Tienhoven, A.M., Otter, L., 2006. Modelled surface ozone over southern Africa during the Cross Border Air Pollution Impact Assessment Project. Environ. Model. Software 21, 911-924. 